\title{
Transmission Electron Microscopy Investigation of Ag Diffusion Mechanisms in $\beta$-SiC
}

\author{
Robert A. Coward ${ }^{1}$, Christopher R. Winkler ${ }^{1}$, William A. Hanson ${ }^{1}$, Michael L. Jablonski ${ }^{1}$, and Mitra L. \\ Taheri $^{1} *$ \\ ${ }^{1}$ Department of Materials Science \& Engineering, Drexel University, Philadelphia, PA \\ *Author to whom correspondence should be addressed: $\underline{\text { taheri@ coe.drexel.edu }}$
}

\begin{abstract}
$\beta$-silicon carbide $(\beta-\mathrm{SiC})$ acts as the main layer for metallic fission product retention in tristructuralisotropic (TRISO) fuel particles. It is critical to track these fission products in the $\beta$-SiC layer to provide a baseline understanding of safe fuel operation for next generation nuclear reactors. In this study, the microstructural evolution of the $\beta$-SiC layer is examined through the comparison of as-implanted and annealed samples up to $1600^{\circ} \mathrm{C}$ using high resolution transmission electron microscopy (HRTEM). Faceted voids were observed in annealed samples but not in the as-implanted samples, suggesting the possibility that a void mediated fission product transport mechanism due to the change in microstructure of the $\beta$-SiC layer at elevated temperatures plays a role in the diffusion of metallic species through the $\beta$-SiC cladding layer. It should be noted, however, that Ag implantation at room temperature is not an ideal method to study Ag diffusion in TRISO fuel particles. Ultimately, Ag implantation should be performed above the critical temperature for which amorphization will not occur to better correlate to conditions in a Generation IV reactor and to see if void formation occurs.
\end{abstract}

\section{Introduction}

Generation IV reactors are being designed to improve nuclear safety, minimize waste, and decrease operating costs. One of these designs is known as the very high temperature reactor (VHTR), which relies on tristructural-isotropic (TRISO) fuel particles that are designed to withstand temperatures up to $1600^{\circ} \mathrm{C}$ [1,2] and microencapsulate fission products to reduce external containment requirements [3]. Utilization of the TRISO fuel particle is also being considered for use in other advanced reactor designs such as fluoride salt high temperature reactors (FHRs) and even for application to existing light water reactors (LWRs) [4,5]. TRISO fuel particles are composed of a fuel kernel coated with the following four layers through chemical vapor deposition (CVD) in a fluidized bed: a porous carbon buffer layer, an inner layer of Pyrolytic Carbon (PyC), a layer of beta silicon carbide $(\beta-\mathrm{SiC})$, and outer layer of PyC. The $\beta$-SiC layer is possibly the most important layer of the particles because it provides structural support and acts as a diffusion barrier to retain fission products at elevated temperatures $[3,5,6,7,8]$.

One of the major obstacles facing the development of VHTRs is the contamination of the reactor due to unwanted diffusion of fission products through the TRISO particles. Some of these products are metallic in nature and include silver, caesium, indium, and palladium [4,7,9]. It has been noted that these metallic elements are able to diffuse through the $\beta$-SiC layer [2,10]. Escape of silver is particularly negative due to its relatively long half-life of approximately 250 days in the form of ${ }^{110 \mathrm{~m}} \mathrm{Ag}[10,11]$ and its tendency to depose on internal systems [7].

Due to these limitations in the fission product containment, additional insight into the transport and diffusion of metallic elements in the $\beta$-SiC layer of TRISO fuel particles is needed. Since the $\beta$-SiC is the key layer, characterizing and studying this layer at high temperatures in the presence of metallic ions is critical to ensure stability and performance. Examining whether there is any microstructural evolution or features giving 
rise to fission product escape, or preferential segregation in the $\beta$-SiC layer, will give a greater insight into the mechanisms responsible for failure of TRISO fuel particles.

Various mechanisms of fission product release from $\beta$-SiC have been suggested, based on both experimental and theoretical evidence $[2,4,7,8,10,12,13,14]$; however, no single mechanism for Ag release from TRISO particles has been confirmed. Multiple aspects of the $\beta$-SiC microstructure have been analyzed with respect to fission product transport. Differences such as grain sizes, grain orientations, boundary types, and mechanical defects all have an effect on how ions diffuse through a material. Many of the deleterious microstructural features in $\beta$-SiC result from growth parameters during CVD. A high density of stacking faults is a characteristic feature of $\beta$-SiC that form during growth by CVD [15]. It is still uncertain whether or not these defects provide a high diffusivity path for metallic ions to penetrate through the $\beta$-SiC layer in TRISO particles. In addition to stacking faults, nanocracks have been suggested as a mechanism for fission transport [2]. Finally, grain size has been investigated recently through trials for the Advanced Gas Reactor Fuel Development and Qualification program's first irradiation experiment (AGR-1) with varying grain sizes of TRISO fuel layers to examine if grain size influences grain boundary diffusion [16]. While some leading theories explain that the transport of $\mathrm{Ag}$ through the $\beta$-SiC layer occurs by grain boundary diffusion [12], there is evidence to show that there are additional mechanism that are likely to play a role [7] such as palladium mitigated transport [8] and surface diffusion [10]. Still others studies have shown that at elevated temperatures, the $\beta$-SiC layer can crack and debond, leading to a possible release mechanism [2], and while this proposed mechanism is not limited to long-lived fission products, it is a possible explanation for their release. It is uncertain whether these previously demonstrated cracks are random imperfections in sample manufacturing or are occurring during irradiation of the TRISO particles. Despite these proposed suggestions, no single mechanism for Ag release from TRISO particles has been agreed upon. In this study, we use high resolution transmission electron microscopy (TEM) to examine and characterize the transport of metallic species in $\beta$-SiC layer post implantation and annealing.

\section{Experimental Methods}

Since $\beta$-SiC grown by CVD on silicon wafers have varying microstructures from different manufacturers due to deposition and growth parameters, all the $\beta$-SiC samples were provided by Rohm and Haas for consistency. All samples in this paper were manufactured by CVD on silicon wafer substrates. The issue with the epitaxial growth of $\beta-\mathrm{SiC}$ is the large difference in coefficients of thermal expansion: approximately $8 \%$ [15]. This leads to a high density of stacking faults, dislocations, and twins forming to relieve those thermal strains. This can be seen in Figure 1, displaying the samples in this study that have a high density of stacking faults. To mitigate this, the $\beta$-SiC was ground down from the top and bottom after CVD to create a uniform grain structure throughout the thickness of the sample. These samples were then implanted with silver at $400 \mathrm{keV} \mathrm{Ag}{ }^{+}$to a fluence of $2 \times 10^{16}$ atoms $/ \mathrm{cm}^{2}$ using ion implantation at room temperature at the Michigan Ion Beam Laboratory. Half of the samples were annealed to $1600^{\circ} \mathrm{C}$ for 60 hours and half remained asimplanted. It should be noted that room temperature implantation is not the ideal set-up for this experiment and that this is below the critical amorphization temperature of $\beta$-SiC.

Samples of as-implanted and annealed-implanted $\beta$-SiC were prepared for transmission electron microscopy using conventional cross-section sample preparation techniques and mechanically polished down to $0.5 \mu \mathrm{m}$ diamond lapping film. This process was followed by ion-milling using a Fishione low angle ion milling and polishing system (model 1010) and a Precision Ion Polishing System (model 691). The electron transparent films were imaged using a JEOL $2100 \mathrm{LaB}_{6}$ TEM to track the transport and segregation of metallic particles pre and post anneal. Diffraction analysis and energy dispersive spectroscopy were used in conjunction with high resolution TEM imaging to analyze specific microstructural features and to confirm the presence of $\mathrm{Ag}$. 


\section{Results and Discussion}

TEM images of the as-received $\beta$-SiC samples are shown in Figure 1, revealing a high density of stacking faults, which was to be expected from CVD growth [17]. Bright field TEM images in Figure 2 then reveal the distribution of $\mathrm{Ag}$ in both the as-implanted and annealed microstructures of $\beta-\mathrm{SiC}$. During ion implantation at room temperature, the surface layer of the implantation layer of the $\beta-\mathrm{SiC}$ is damaged, but through annealing a recrystallization process occurs [18]. Bright field energy dispersive spectroscopy, shown in Figure 3, and dark field TEM imaging were used in conjunction with high resolution TEM imaging to confirm that the clusters in Figure 2 consisted of Ag. Figure 2 shows that the sample was amorphized by the Ag ion implantation, but appeared to have recrystallized after going through an annealing process. This is corroborated by selected area diffraction patterns seen in Figure 4 that show both the amorphous as-implanted and the newly recrystallized surface region of the $\beta$-SiC layer. The recrystallized region is indexed in Figure 8 showing the cubic structure of $\beta$-SiC. It has been shown that $\beta$-SiC is amorphized by ion implantation at room temperature, while at an elevated ion implantation temperature range of above $350^{\circ} \mathrm{C}$ this amorphization does not occur $[19,20]$; so some of the resulting structures after annealing may be solely due to the implantation temperature. There have also been studies on $\alpha$-SiC showing thermal etching or decomposition effects at higher temperatures, particularly above $1200^{\circ} \mathrm{C}$. Structural changes that have been observed include clustering, faceting and etching of grains at elevated temperatures [21]. The damage from the implantation has also been shown to have an impact on the oxidation of $\alpha-\mathrm{SiC}$ [22]. Since some of the samples examined in this current study were annealed to a temperature of $1600^{\circ} \mathrm{C}$, it is possible we are seeing some of these same structural changes.

Figure 2 highlights a different particle density in the annealed sample compared to the as-implanted sample. This could be a result of $\mathrm{Ag}$ clustering during annealing. To quantify trends in Ag clustering that might have occurred during annealing, particle size analysis was conducted for both the asimplanted and annealed-implanted samples, shown in Figure 5. The as-implanted average particle area was $96 \mathrm{~nm}^{2}$, while the annealed average particle area was $152 \mathrm{~nm}^{2}$. The analysis revealed a higher density of particles in the as-implanted samples compared to
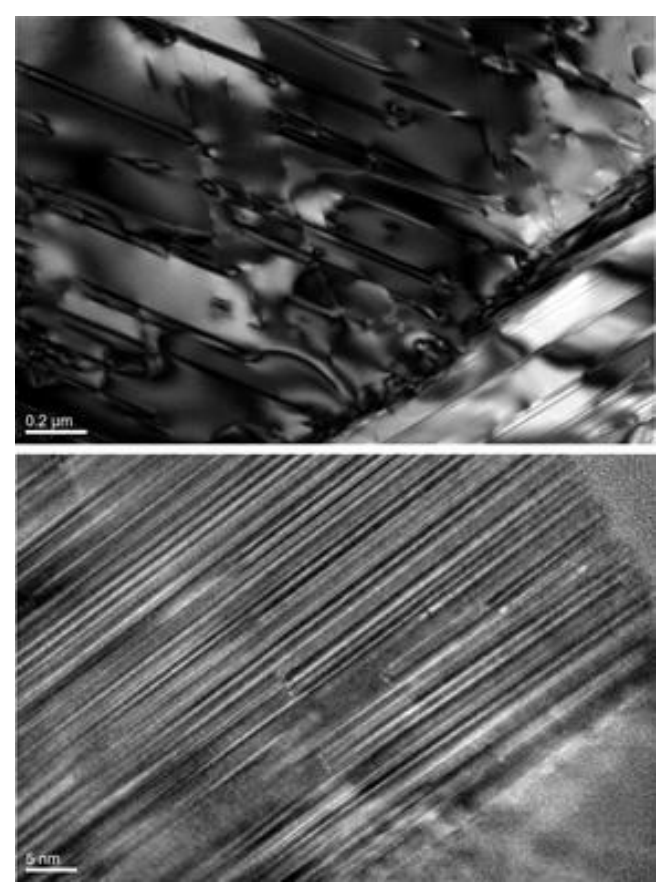

Figure 1: Low magnification (top) and high resolution (bottom) TEM images showing a high density of nano-twins and stacking faults introduced into $\beta$-SiC during thermal strain relief.

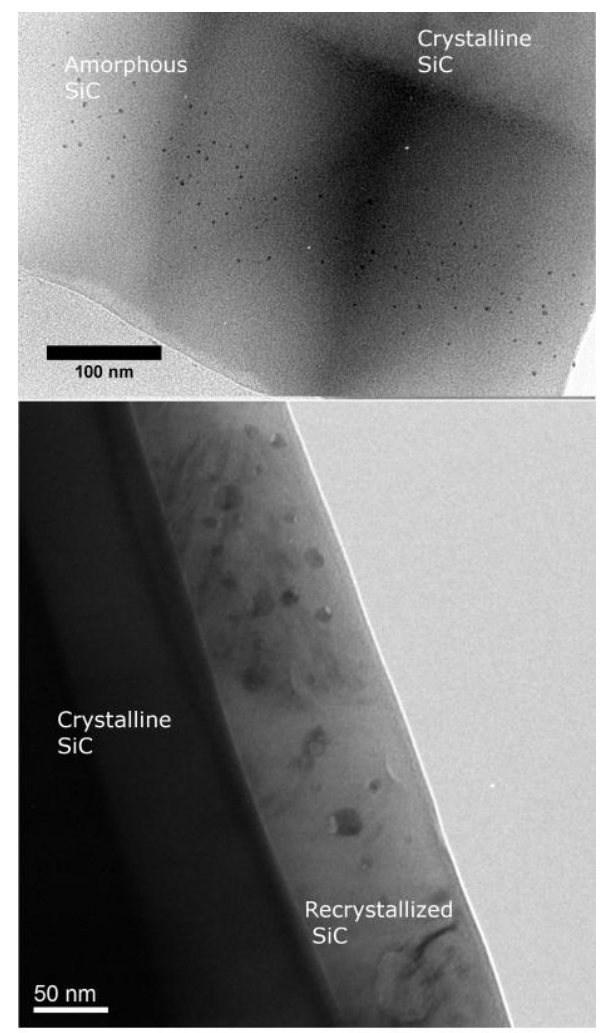

Figure 2: Low magnification TEM images of $\beta$-SiC in the amorphized, as-implanted condition (top) and the recrystallized, as-annealed condition (bottom), demonstrating changes in size and shape of $\mathrm{Ag}$ clustering which appear as darks particles in the micrographs. 
the annealed-implanted samples in the same amount of area. The particles in the as-implanted samples also had a smaller average size, supporting the theory that Ag could be agglomerating during the annealing process. It should be noted that it is possible that some of the Ag could have escaped during the annealing process by diffusing through the front or sides and thus out of the sample [23]. However, regardless of this potential loss of Ag from the sample, there is a distinct diffusion and resulting redistribution of particles during the annealing process.
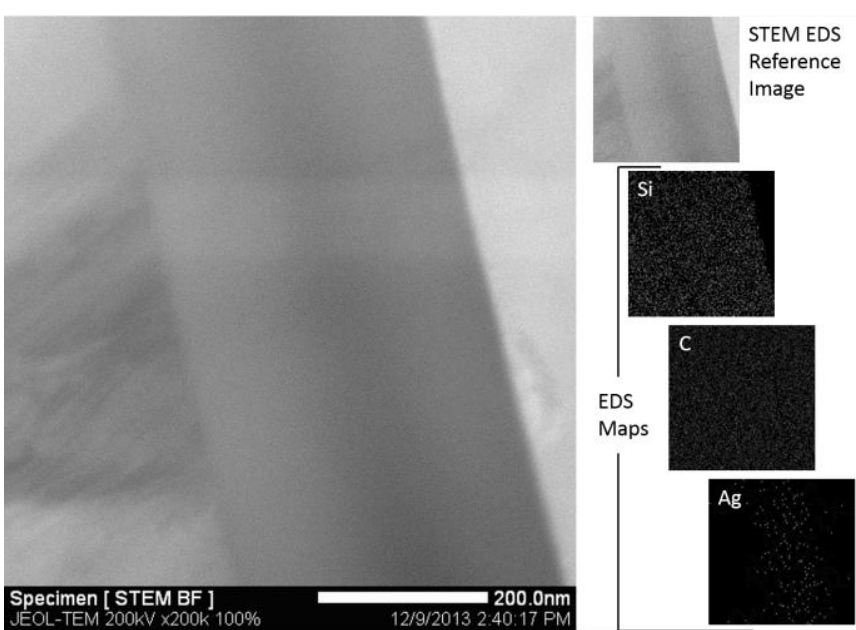

Figure 3: Bright field scanning transmission election microscopy and energy dispersion $\mathrm{x}$-ray spectroscopy elemental maps showing distribution of $\mathrm{Ag}$ in $\beta$-SiC in the as-implanted condition. Within the STEM image from left to right is the crystalline $\beta$-SiC, the amorphized $\beta-\mathrm{SiC}$ and an epoxy layer. This clearly shows that the Ag implantation distribution places it mostly within the armorphised $\mathrm{SiC}$ region, though it should be noted that there is a minor silver presence within the crystalline $\beta-\mathrm{SiC}$.
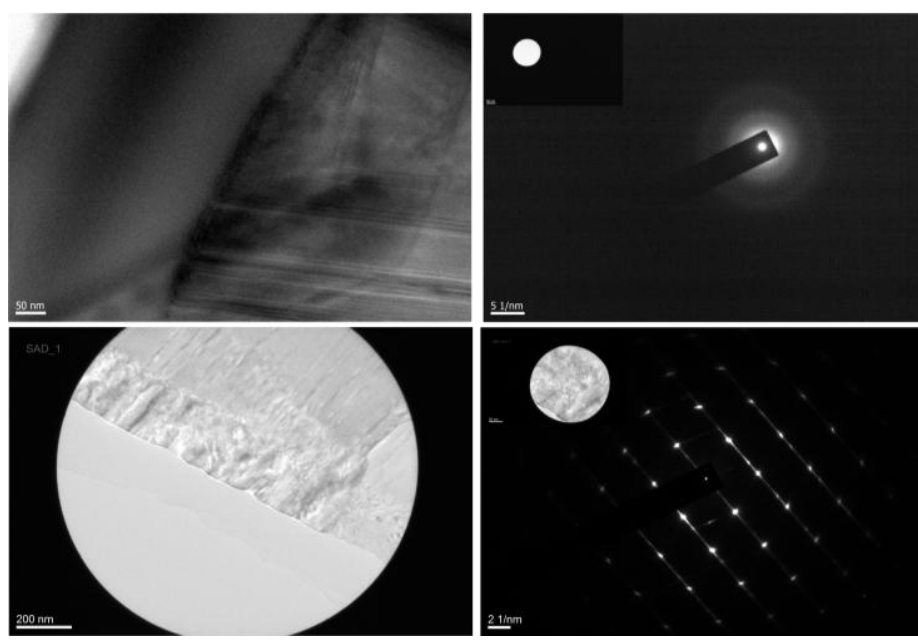

Figure 4: Selected area diffraction patterns (SADP) with corresponding selected area (SA) images inset in the corner of $\beta-\mathrm{SiC}$ in the amorphous, as-implanted condition (top right) and recrystallized, as-annealed condition (bottom right); and low magnification TEM images showing the regions for SADP and SA images for the amorphous, as-implanted condition (top left) and the recrystallized, as-annealed condition (bottom left).

\section{Ag Particle Size Analysis}

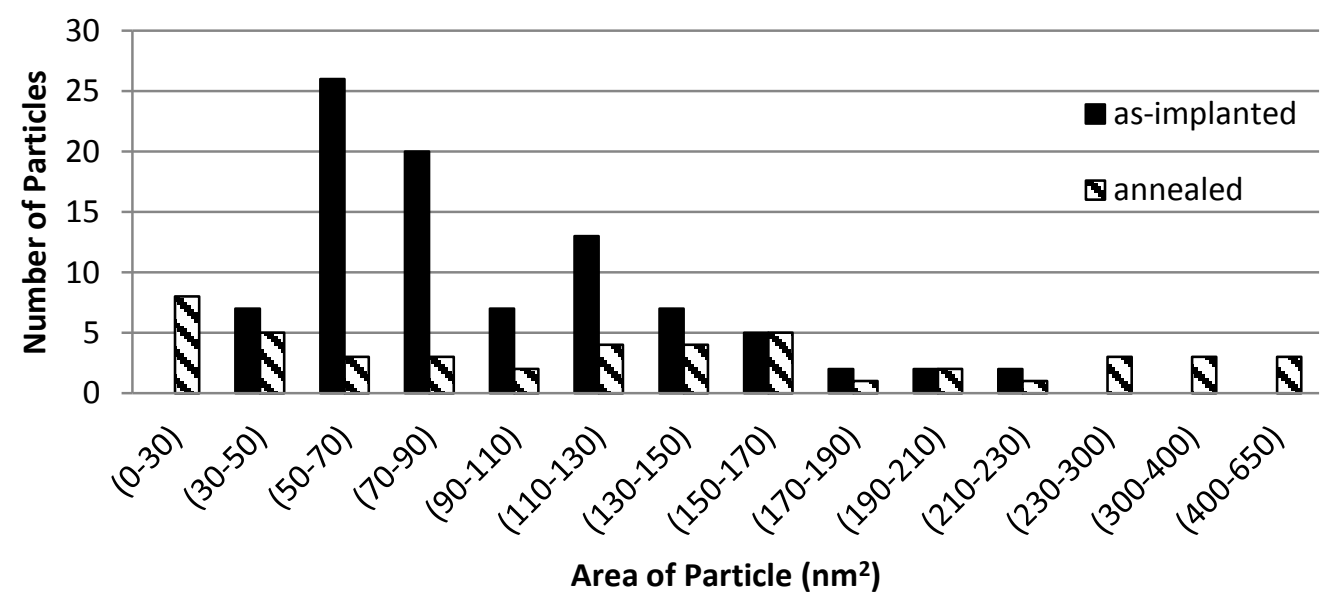

Figure 5: Particle size analysis of Ag clusters in amorphous, as-implanted (blue) and recrystallized, as-annealed (red) $\beta-\mathrm{SiC}$. 
High resolution TEM (HRTEM) images of annealed-implanted $\beta$-SiC revealed the presence of voids around the Ag particles as shown in Figure 6. To confirm that these microstructural features were, in fact, voids or a low density phase, multiple TEM focal series were performed which showed the appropriate Fresnel contrast on the edges of the voids. The focal series methodology used was based on previously documented TEM studies showing that voids appear white surrounded by a dark Fresnel fringe while underfocused, and conversely, appear black surrounded by a bright fringe while overfocused [24]. This is due

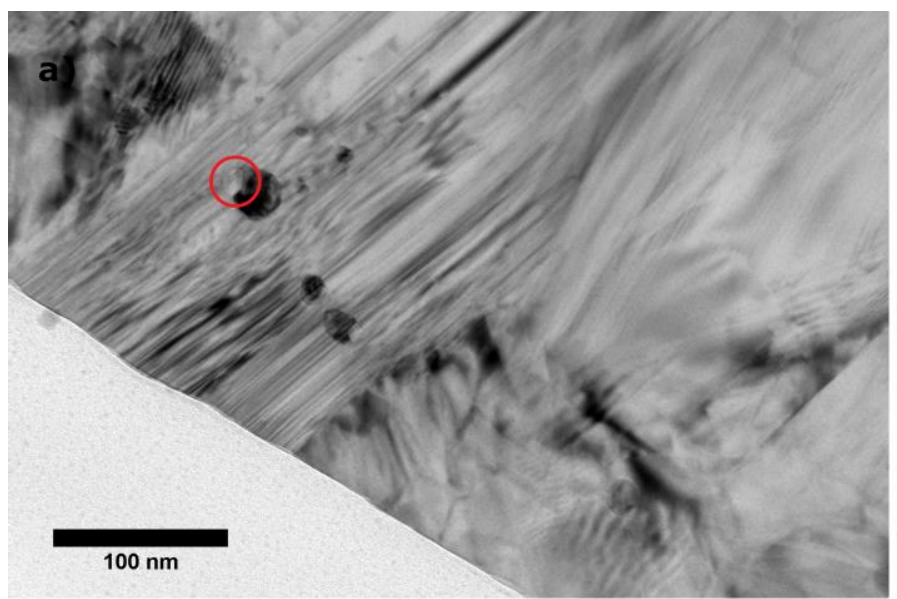

b)
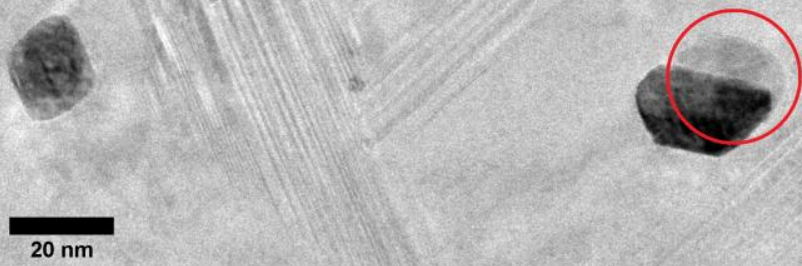

Figure 6: Low magnification (a) and high magnification (b) bright field TEM imaging of SiC in the annealed recrystallized condition showing voids, visible as white Fresnel fringes, around the Ag particle clustering. Focal series were performed on these particles to confirm that these fringes are voids.

to the fact that there is phase contrast between a column of electrons passing through a void compared to electrons passing through material around the void. An example of one of these focal series is shown in Figure 7. This clearly shows the appropriate contrast to confirm that these particles are surrounded by voids. Note that the smaller black particles on the annealed sample surface are sputter redeposition from the ion milling process.

Further HRTEM analysis revealed that the voids in the annealed-implanted $\beta$-SiC are faceted, seen clearly in Figure 8. An assumption was made that the voids in these samples mimic the observed facets throughout the entire volume of the void structure since only two dimensions of the void structure can be seen

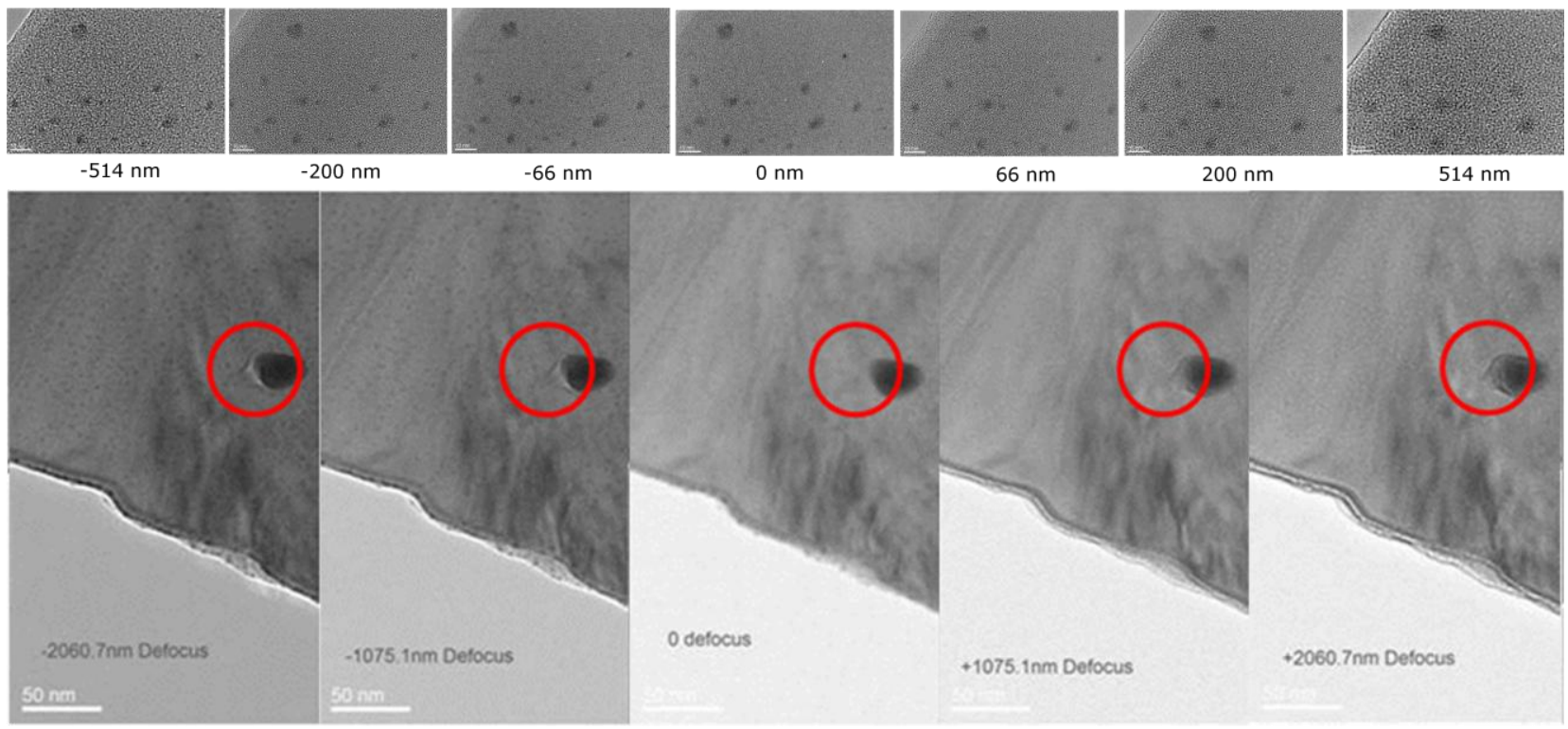

Figure 7: One of the focal series of $\beta$-SiC demonstrating that $\mathrm{Ag}$ particles are surrounded by voids in both the amorphous, as-implanted condition (top) and recrystallized, as-annealed condition (bottom). 
in the images. That being said the sample is not thin enough to slice through the Ag particle and void without a slice of the surrounding SiC. This is exhibited in Figure 8 as a projection of the surrounding SiC lattice on the Fresnel contrast induced by the voids. Fast Fourier transforms (FFTs), which contain diffraction (reciprocal space) information, of the facets were generated and indexed using CrystalMaker ${ }^{\mathrm{TM}}$ software to calculate the dspacing of planes of $\beta-\mathrm{SiC}$, and to quantify orientation information in the voids. With the calculated d-spacings, it was possible to index the facets, with the results shown in Figure 8. It has been noted that the number of vacancies being produced by the ion implantation could give rise to a transport mechanism [7]. Since the activation energies for vacancy jumps in $\beta$-SiC were calculated as follows: $\mathrm{E}_{\text {act }}\left(\mathrm{V}_{\mathrm{C}}\right)=3.5 \mathrm{eV}$ and $\mathrm{E}_{\mathrm{act}}\left(\mathrm{V}_{\mathrm{Si}}\right)=$ $3.4 \mathrm{eV}$, it is not likely that vacancies will quickly anneal out of the $\beta-\mathrm{SiC}$ and thus be removed from the sample and as a result the diffusion mechanism [25] which supports the presence of voids rather than a low density phase surrounding the Ag clusters. By doing a comparison of total particle area, it was calculated that in the asimpanted samples there was approximately $8700 \mathrm{~nm}^{2}$ of particle area, while in the annealed sample there was only $7100 \mathrm{~nm}^{2}$ of particle area. However, an assumption has to be made when comparing these results that the sample was evenly implanted with Ag in the lateral direction such that lateral variation that results from sample preparation does not impact final results. The voids were only present in the annealed samples which suggest that a possible transport mechanism is activated for the $\mathrm{Ag}$ particles when the implanted amorphous region recrystallizes during the annealing process. This could happen through the nucleation of voids around Ag

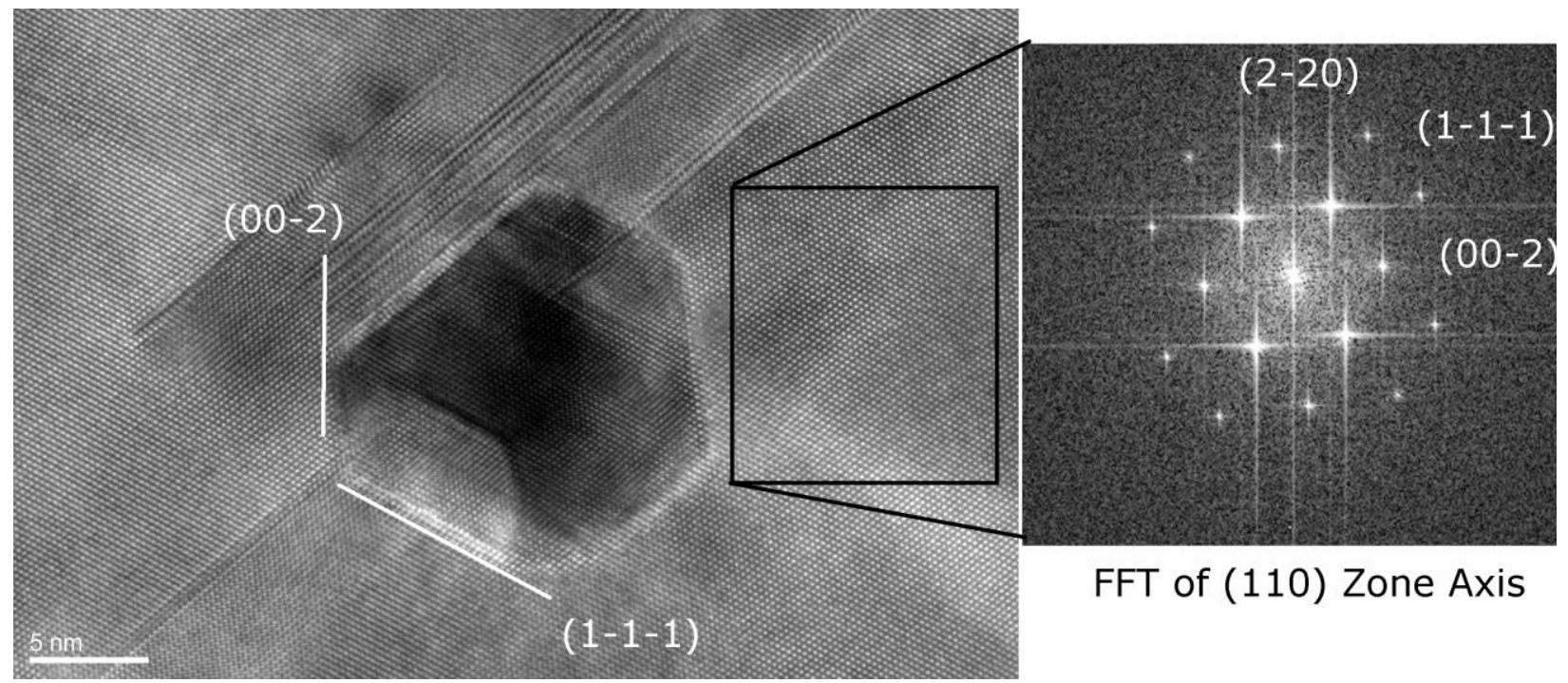

Figure 8: High resolution TEM image of $\beta$-SiC in the as-annealed condition (left) showing an indexed, faceted void surrounding an Ag particle and an indexed FFT of the surrounding crystal structure (right). It should be noted that the lattice exhibited within the void structure is a projection of the surrounding $\mathrm{SiC}$ structure.

particles that then act as high diffusivity surfaces for the Ag thus mediating the coarsening of Ag agglomerations. Further analysis will also help to shed light on the specific facets that the voids appear to form along. It should also be noted that it is unclear if the high density of stacking faults could possibly provide a mechanism for high diffusivity.

The apparent evidence of void creation and the observed agglomeration of $\mathrm{Ag}$ particles all during annealing up to $1600^{\circ} \mathrm{C}$ are important pieces to understanding how $\mathrm{Ag}$ behaves in $\beta$-SiC. It is unclear if the voids being produced could agglomerate and provide a means for a void mediated transport of particles. Further analysis of the voids will also help to shed light on the specific facets that the voids appear to form along. It is necessary for the actual formation of voids to be observed in situ in the TEM through heating experiments. This method of investigation is most likely the best method for determining another source Ag particle escape. 


\section{Conclusion}

In this study, the microstructural evolution of the $\beta$-SiC layer is examined through the comparison of asimplanted and annealed samples up to $1600^{\circ} \mathrm{C}$ using high resolution transmission electron microscopy (HRTEM).

Under examination in the transmission electron microscope (TEM), faceted voids were observed around the Ag particles after annealing. This gives way to the possible theory of a void mediated transport mechanism due to the change in microstructure of the $\beta$-SiC layer at elevated temperatures. In addition, the implanted $\mathrm{Ag}$ particles appear to agglomerate during annealing.

Our observations support evidence of void creation and the agglomeration of Ag particles all during annealing up to $1600^{\circ} \mathrm{C}$, which are key pieces of information in the understanding one of the potential release mechanisms of fission products from TRISO fuel particles. This possibility of a void mediated fission product transport mechanism could be due to the change in microstructure of the $\beta$-SiC layer at elevated temperatures, and can have a role in the diffusion of metallic species through the $\beta$-SiC cladding layer. The mechanism proposed in this study is likely not the only contributor to fission product release. As such, additional studies are underway to determine the overall role of the voids found, and how they contribute to or function alongside other mechanisms such as micro-cracking or debonding of $\beta$-SiC. It should also be noted that the amount and type of damage introduced into the $\beta$-SiC by ion implantation is specific to the element being implanted [18, 20]. This motivates the need to characterize various implantations of metallic fission products in future studies.

As previously stated in the abstract, ideal conditions that would most suitably mimic conditions TRISO particles would experience would be implantation above the critical amorphization temperature of the $\beta$-SiC as opposed to implantation at room temperature. It is possible that the voids are a result of the damaged amorphous layer of $\beta$-SiC recrystallizing which may not occur if implanted at higher temperatures. Another possibility is structural changes at elevated temperatures due to thermal etching or decomposition. This study does however give insight into $\mathrm{Ag}$ behavior within $\mathrm{CVD} \beta$-SiC that has been implanted at room temperature.

\section{Acknowledgements}

All authors acknowledge financial support from the Department of Energy through the Nuclear Energy University Program (NEUP) grant \#00103195. All authors acknowledge Dr. Gary S. Was and Shyam Dwaraknath from the Department of Materials Science and Engineering and the Department of Nuclear Engineering at the University of Michigan for providing the samples, performing ion irradiation of the samples utilizing the Michigan Ion Beam Laboratory, and providing feedback in developing this article. Authors R.C. and W.H. also acknowledge Dr. Craig Johnson and the staff of the Centralized Research Facility at Drexel University for TEM training assistance and constructive discussions.

\section{References}

[1] I. Hore-Lacy. Nuclear Energy in the $21^{\text {st }}$ Century. World Nuclear University Press. (2006)

[2] K. Minato, T. Ogawa, K. Fukuda, and H. Sekino, "Release behavior of metallic fission products from HTGR fuel particles at 1600 to $1900^{\circ}$ C." Journal of Nuclear Materials, Vol. 202 (1993) 47-53. doi: 10.1016/0022-3115(93)90027-V

[3] K. A. Terrani, L. L. Snead, J. C. Gehin. "Microencapsulated fuel technology for commercial light water and advanced reactor application.” Journal of Nuclear Materials. 427 (2012) 209-224. doi:

10.1016/j.jnucmat.2012.05.021

[4] Y. Katoh, L. L. Snead, I. Szlufarska, W. J. Weber. "Radiation effects in SiC for nuclear structural applications." Current in Solid State and Materials Science. 16 (2012) 143-152. doi:

10.1016/j.cossms.2012.03.005

[5] P. Hosemann, J. N. Martos, D. Frazer, G. Vasudevamurthy, T. S. Byun, J. D. Hunn, B. C. Jolly, K. Terrani, M. Okuniewski. "Mechanical characteristics of SiC coating layer in TRISO fuel particles." Journal of Nuclear Materials. 442 (2013) 133-142. doi: 10.1016/j.jnucmat.2013.08.041 
[6] W. Jiang, W.J. Weber, V. Shutthanandan, L. Li, S. Thevuthasan, "Thermal and dynamic responses of Ag implants in silicon carbide," Nuclear Instruments and Methods in Physics Research B, 219-220 (2004) 642-646. doi: 10.1016/j.nimb.2004.01.134

[7] D. Shrader, S. M. Khalil, T. Gerczak, T. R. Allen, A. J. Heim, I. Szlufarska, D. Morgan. "Ag diffusion in cubic silicon carbide." Journal of Nuclear Materials. 408 (2011) 257-271. doi: 10.1016/j.jnucmat.2010.10.088 [8] J. H. O'Connell, J. H. Neethling. "Ag transport in high temperature neutron irradiated 3C-SiC" Journal of Nuclear Materials. 445 (2014) 20-25. doi: 10.1016/j.jnucmat.2013.10.050

[9] John R. Lamarsh, Anthony J. Baratta. Introduction to Nuclear Engineering. $3^{\text {rd }}$ ed. Prentice Hall (2001) [10] H. Y. Xiao, Y. Zhang, L. L. Snead, V. Shutthanandan, H. Z. Xue, W. J. Weber. "Near-surface and bulk behavior of Ag in SiC." Journal of Nuclear Materials. 420 (2012) 123-130. doi: 10.1016/j.jnucmat.2011.09.028 [11] R.B. Firestone, V.S. Shirley, C.M. Baglin, S.Y.F. Chu, J. Zipkin. Table of Isotopes. $8^{\text {th }}$ ed. John Wiley and Sons. New York. (1995)

[12] T. J. Gerczak, L. Tan, T. R. Allen, S. Khalil, D. Shrader, Y. Liu, D. Morgan, I. Szlufarska. "Experimental and simulation insight on the transport of silver fission product in SiC," Proceedings of the $4^{\text {th }}$ International Topical Meeting on High Temperature Reactor Technology, Vol 2. Washington, DC. (2008) 715-723. doi: 10.1115/HTR2008-58131

[13] H. J. MacLean, R. G. Ballinger, L. E. Kolaya, S. A. Simonson, N. Lewis, M. E. Hanson. "The effect of annealing at $1500^{\circ} \mathrm{C}$ on migration and release of ion implanted silver in CVD silicon carbide." Journal of Nuclear Materials, Vol. 357 Iss. 1-3 (2006) 31-47. doi: 10.1016/j.jnucmat.2006.05.043

[14] T. T. Hlatshwayo, J. B. Malherbe, N. G. van der Berg, L. C. Prinsloo, A. J. Botha, E. Wendler, W. Wesch. "Annealing of silver implanted $6 \mathrm{H}-\mathrm{SiC}$ and the diffusion of the silver." Nuclear Instruments and Methods in Physics B. 274 (2012) 120-125. doi: 10.1016/j.nimb.2011.12.006

[15] P. Friedrichs, K. Tsunenobu. Silicon Carbide: Growth, Defects, and Novel Applications. $1^{\text {st }}$ ed. WileyVCH (2009)

[16] R. Kirchhofer, J. D. Hunn, P. A. Demkowicz, J. I. Cole, B. P. Gorman. "Microstructure of TRISO coated particles from the AGR-1 experiment: SiC grain size and grain boundary character." Journal of Nuclear Materials. 432 (2013) 127-134. doi: 10.1016/j.jnucmat.2012.08.052

[17] N. G. Van der Berg, J. B. Malherbe, A. J. Botha, E. Friedland. "SEM analysis of the microstructure of the layers in triple-coated isotropic (TRISO) particles.” Surface and Interface Analysis. Vol. 42 Iss. 6-7 (2010) 1156-1159. doi: 10.1002/sia.3266

[18] C. J. Mchargue and J. M. Williams. "Ion implantation effects in silicon carbide," Nuclear Instruments and Methods in Physics Research. Vol. 80-81 (1993) 889-894. doi: 10.1016/0168-583X(93)90703-9

[19] J. B. Malherbe. "Diffusion of fission products and radiation damage in SiC." Journal of Physics D: Applied Physics. 46 (2013) 473001

[20] E. Friedland, T. Hlatshwayo, N. G. van der Berg. "Influence of radiation damage on diffusion of fission products in silicon carbide.” Physica Status Solidi (C), 10(2) (2013), 208-215. doi:10.1002/pssc.201200457 [21] N.G van der Berg, J. B. Malherbe, A.J. Botha, E. Friedland. "Thermal etching of SiC." Applied Surface Science, 258 (2012), 5561-5566. doi:10.1016/j.apsusc.2011.12.132

[22] S. Muto, H. Sugiyama, T. Kimura, T. Tanabe, T. Maruyama. "EXELFS / ELNES study of electron irradiation-induced oxidation of $\alpha$-SiC." Nuclear Instruments and Methods in Physics Research B, 218, (2004) 117-122. doi:10.1016/j.nimb.2003.12.001

[23] S. Dwaraknath, G. S. Was. "Development of a multi-layer diffusion couple to study fission product transport in $\beta$-SiC." Journal of Nuclear Materials. 444 (2013) 170-174. doi: 10.1016/j.jnucmat.2013.09.040 [24] M. L. Jenkins, M. A. Kirk. Characterization of Radiation Damage by Transmission Electron Microscopy. $1^{\text {st }}$ ed. Institute of Physics, 2001

[25] E. Rauls, T. Frauenheim, A. Gali, P. Deák. Theoretical study of vacancy diffusion and vacancy-assisted clustering of antisites in SiC. Physical Review B, 68. 155208 (2003) 1-9. doi: 10.1103/PhysRevB.68.155208 